\title{
Jean Bessière, Inactualité et originalité de la littérature française contemporaine
}

\section{Francesca Lorandini}

\section{(2) OpenEdition}

9 Journals

\section{Edizione digitale}

URL: http://journals.openedition.org/studifrancesi/1457

DOI: 10.4000/studifrancesi. 1457

ISSN: 2421-5856

\section{Editore}

Rosenberg \& Sellier

\section{Edizione cartacea}

Data di pubblicazione: 1 décembre 2015

Paginazione: 630

ISSN: 0039-2944

\section{Notizia bibliografica digitale}

Francesca Lorandini, «Jean Bessière, Inactualité et originalité de la littérature française contemporaine», Studi Francesi [Online], 177 (LIX | III) | 2015, online dal 01 décembre 2015, consultato il 07 janvier 2021. URL: http://journals.openedition.org/studifrancesi/1457 ; DOI: https://doi.org/ERREUR PDO dans / localdata/www-bin/Core/Core/Db/Db.class.php L.34 : SQLSTATE[HY000] [2006] MySQL server has gone away

Questo documento è stato generato automaticamente il 7 janvier 2021.

\section{(c) (i) (9)}

Studi Francesi è distribuita con Licenza Creative Commons Attribuzione - Non commerciale - Non opere derivate 4.0 Internazionale. 


\title{
Jean Bessière, Inactualité et originalité de la littérature française contemporaine
}

\author{
Francesca Lorandini
}

\section{NOTIZIA}

JEAN BESSIÈRE, Inactualité et originalité de la littérature française contemporaine, Paris, Champion, 2014 («Unichamp Essentiel», 34), pp. 232.

1 Partendo dalla resistenza che la letteratura e la critica francesi sembrano opporre alle categorie di «postmoderno» $\mathrm{e}$ "postcoloniale», Bessière propone una visione d'insieme in chiave paradossale del periodo che va dagli anni Settanta ad oggi. La narrativa e la poesia francesi rappresenterebbero un caso isolato sulla scena internazionale poiché si sarebbero mostrate a un tempo attuali e inattuali: caratterizzate, cioè, da un lavorio teorico-critico costante che ha comportato un distacco dalla pura fattualità, ma sorretto da una ferma ambizione di lettura del contemporaneo. Un contemporaneo che è da intendersi nell'ottica di Marc Augé, come attualità messa costantemente in prospettiva: una giustapposizione temporale che contiene un'interpretazione del passato che è anche un'ipotesi o una proposta di futuro - un tempo paradossale, per l'appunto. Con il piglio combattivo che reggeva Qu'est-il arrivé aux écrivains français?, Bessière descrive e interpreta la dualità irriducibile che sarebbe presente nella letteratura francese contemporanea: da un lato, una corrente fedele a quella «tradition du nouveau» di cui parlava il critico d'arte Harold Rosenberg già alla fine degli anni Cinquanta, una letteratura di spirito avanguardistico, totalizzante, che ambisce a inglobare il mondo ed è votata a mimarne il funzionamento, la meccanica; dall'altro, una corrente che rifiuta le ambizioni olistiche di quel tipo di tradizione e, pur veicolando una riflessione sulla dialettica tra «poïesis» e «autopoïesis» che fonderebbe la creazione letteraria, rifiuta di pensare la letteratura come «mêmeté». Da una parte, quindi, una «littérature puissance» che manifesta una fiducia sconfinata nell'esercizio 
stesso della scrittura (esemplari, in questo senso, sono L'Invention du monde di Olivier Rolin e Les Ruines de Paris di Jacques Réda); dall'altra una volontà tenace di svincolarsi da questa prospettiva (Littell, Houellebecq, il giallo, la fantascienza, la letteratura della Shoah, della colonizzazione, dell'identità sessuale e dell'identità di genere, ma anche Chevillard e Novarina).

2 Il saggio è organizzato in tre sezioni: la prima propone un'analisi contrastiva di queste due modalità attraverso cui la letteratura tenterebbe di situarsi in un contesto in cui il flusso di informazioni ha la meglio sul referente. Nella seconda sezione Bessière mette in luce il «malaise de la modernité» che emergerebbe dalle contraddizioni inerenti alla «tradition du nouveau» (ambizione universalistica-dichiarazione di marginalità; descrizione del presente - pretesa di transtemporalità), polemizzando apertamente con il discorso degli scrittori e dei critici legati, anche inconsapevolmente, a questo tipo di tradizione. Nella terza sezione viene infine analizzata quella parte della letteratura francese che, rifiutando di ricercare il nuovo ad ogni costo, riesce a proporre sia una riflessione sulla rappresentazione e sulla temporalità che un'interpretazione delle proprie condizioni d'esistenza nel nostro tempo. 